\title{
OS PRINCÍPIOS DE SANTIAGO PARA OS FUNDOS SOBERANOS DE INVESTIMENTO: UMA ANÁLISE TEÓRICA
}

\author{
THE SANTIAGO PRINCIPLES FOR THE SOVEREIGN WEALTH FUNDS: A THEORETICAL \\ ANALYSIS
}

\begin{abstract}
Resumo
Este artigo analisa os Princípios de Santiago nos termos de um regime internacional em formação. Frente à ameaça de protecionismo financeiro por países apreensivos quanto à atuação de Fundos Soberanos de Investimento, estes princípios despontam como proposta de regulamentação neste âmbito. Não obstante, seu caráter estritamente voluntário suscita dúvidas e incredulidade quanto à sua real eficácia (PARK; ESTRADA, 2011). Diante de tais incertezas, o presente artigo verifica a hipótese de que os Princípios de Santiago representam, na realidade, um regime internacional em formação, que pode levar à ascensão de uma identidade coletiva entre seus participantes. Esta hipótese é sustentada pelas teorias de Krasner (1982) e de Keohane (1984), que proporcionam a base teórica acerca de regimes internacionais, e de Wendt (1999), que fundamenta a construção dessa possível identidade coletiva. Por meio das lentes teóricas desses autores, associadas aos estudos realizados pelo Fórum Internacional dos Fundos Soberanos de investimento, chega-se à confirmação da hipótese proposta.

Palavras-chave: Fundos Soberanos de Investimento; Princípios de Santiago; Regime internacional; Identidade coletiva.
\end{abstract}

\begin{abstract}
This article analyses the Santiago Principles as an international regime in formation. With the threat of financial protectionism by concerned countries with Sovereign Wealth Funds' acts, these principles appear as a proposal for regulation in this area. However, their strictly voluntary character generates doubts and incredulity against their efficacy (PARK; ESTRADA, 2011). In face of these concerns, this article presents the hypotheses that the Santiago Principles represent an international regime in formation, which could bring to the formation of a collective identity among its participants. This hypothesis is sustained by Krasner's (1982) and Keohane's (1984) theories, who provide the theoretical basis about international regimes, and by Wendt's (1999), who instantiates the construction of this possible collective identity. Through these authors' theoretical lens, associated with studies by the International Forum of Sovereign Wealth Funds, the presented hypothesis is confirmed.

Key-words: Sovereign Wealth Funds; Santiago Principles; International regime; Collective identity;
\end{abstract}

\section{INTRODUÇÃO}

O conjunto de processos que se convenciona chamar de globalização financeira apresenta como uma de suas consequências a diminuição do papel dos Estados neste âmbito, de modo a eliminar a intervenção destes no fluxo internacional de capitais. Não obstante, ao constituir Fundos Soberanos de Investimento, alguns países passam a atuar como investidores no tabuleiro financeiro global, recobrando, 
nesta nova forma, um papel de destaque no mundo financeiro (ARIENTI; VIERA, 2013). Esta situação começa a se tornar problemática a partir do momento em que ameaça suscitar a adoção de medidas de protecionismo financeiro por países que, inseguros quanto às reais intenções desses fundos de investimento estatais, começam a articular barreiras a suas ações (COHEN, 2009).

Diante deste contexto, a partir da articulação de alguns países junto a organismos internacionais, os Princípios de Santiago constituem-se como proposta de regulamentação para a atuação dos Fundos Soberanos de Investimento. Entretanto, o caráter voluntário de adesão a esses princípios faz com que alguns o vejam com certa incredulidade e duvidem de sua eficácia, o que origina questionamentos quanto a sua real utilidade (Ibidem). A partir deste panorama, este artigo se propõe a verificar a hipótese de que os Princípios de Santiago constituem um regime internacional emergente, em torno do qual se pode vislumbrar a formação de uma identidade coletiva. Esta realidade permite compreender tanto a razão de sua adoção voluntária por parte dos Estados quanto os benefícios deles provenientes. A confirmação desta hipótese encontra respaldo teórico no neoinstitucionalismo de Krasner (1982) e Keohane (1984), que fundamentará a discussão acerca deste regime internacional, e no construtivismo positivista de Wendt (1999), que proporcionará reflexões acerca da formação de uma identidade coletiva. Ademais, relatórios divulgados pelo Fórum Internacional dos Fundos Soberanos de Investimento conferem sustentação empírica ao argumento que será desenvolvido.

Nesse sentido, este artigo se organiza a partir de quatro seções, além desta introdução e de uma conclusão. Assim, a primeira seção visa a discorrer acerca dos principais aspectos que envolvem os Fundos Soberanos de Investimento e os Princípios de Santiago. Na segunda seção, apresenta-se as teorias de Krasner (1982) e de Keohane (1984), acerca de regimes internacionais, e o construtivismo positivista de Wendt (1999), de modo a, nesta teoria, se conferir especial enfoque à formação de identidades coletivas. Isso possibilita que, na seção subsequente, proceda-se à analise dos Princípios de Santiago à luz das ideias desses autores e que, na quarta seção, discuta-se os dados apresentados pelo Fórum Internacional dos Fundos Soberanos de Investimento dentro da lógica delineada. Tais procedimentos viabilizam concluir que os Princípios de Santiago correspondem a um regime internacional emergente em torno do qual se pode constituir uma identidade coletiva - o que confirma, finalmente, o argumento trabalhado.

\section{OS FUNDOS SOBERANOS DE INVESTIMENTO E OS PRINCÍPIOS DE SANTIAGO}

Desde a década de 1980, com o fim do sistema de Bretton Woods e a implantação de reformas neoliberais, o sistema financeiro internacional vem se configurando de modo a conferir maior mobilidade e liberdade ao capital financeiro privado. No contexto do que se convenciona chamar de globalização financeira, agentes privados, como investidores institucionais, passaram a adquirir protagonismo na operação do regime que a lógica neoliberal impôs ao mundo das finanças (ARIENTI; VIEIRA, 2013). A ideologia subjacente a essa nova organização é a de uma alocação ótima do capital, que, em um contexto de integração financeira global, tenderia a fluir na direção das melhores oportunidades em termos de maior lucro e de menor risco (CARVALHO, 2004). Nesse sentido, uma consequente característica dessa 
realidade seria a redução do papel dos Estados no sistema financeiro internacional, que não mais deveriam interferir em seus mercados financeiros domésticos, abdicando, assim, de qualquer intervenção neste setor, interna ou externamente.

Entretanto, uma nova conjuntura no comércio internacional viria a proporcionar as condições de um outro papel a ser desempenhado pelos Estados nessa configuração da estrutura financeira global. Isso porque, a partir do final da década de 1990 e principalmente ao longo da primeira década do século XXI, alguns países obtiveram um grande aumento no volume de suas reservas internacionais, sobretudo devido à alta dos preços das commodities (COHEN, 2009). Como consequência, para otimizar a utilidade desses recursos, esses Estados promoveram a criação de Fundos Soberanos de Investimento (FSI), por meio dos quais passaram a atuar como investidores no sistema financeiro internacional (PARK; ESTRADA, 2011).

Não há consenso na literatura especializada em torno de uma definição para esses fundos, assim como tampouco há um modelo genérico que possa exemplificá-los. Cada FSI possui suas especificidades, o que pode ser ilustrado, por exemplo, pela grande variedade no volume de ativos financeiros com que operam. Não obstante, pode-se considerar que alguns elementos são imprescindíveis para que se constituam como tal, já que, como regra, são fundos de propriedade estatal, sem passivos significativos e desvinculados administrativamente dos bancos centrais de seus países (COHEN, 2009). Nesse sentido, observa-se que mesmo o Fundo Monetário Internacional (FMI) opta por uma definição abrangente ao defini-los apenas como fundos ou arranjos de investimentos, com propósito especial, e de propriedade do Estado (XAVIER JR., 2014).

Apesar de não ter sido até então um fenômeno inédito ${ }^{1}$, é no século XXI que os FSI passam a apresentar grande peso no sistema financeiro internacional, com estimativas apontando que, ao final de 2008, operavam com volumes de ativos em torno de \$3,9 trilhões (COHEN, 2009). Um exemplo relevante desses fundos é a criação, pelo governo chinês, do China Investiment Coorporation (CIC), ocorrida em 2005 em consequência dos grandes superávits comerciais do país. Outra iniciativa emblemática foi o National Welfare Fund, criação do governo da Rússia, em 2008, frente a seu fortalecimento econômico que se vinha observando. Por fim, cabe também destacar a iniciativa brasileira, ocorrida no mesmo ano, de criar o Fundo Soberano Brasileiro, cujo um dos objetivos declarados seria o de "fomentar projetos de interesse estratégico do país localizado no exterior" (XAVIER JR., 2014).

Estes três exemplos supracitados ajudam a ilustrar as polêmicas advindas da atuação dos FSI. Isso porque a possibilidade de que sejam utilizados como instrumento para a consecução de fins políticos - não sendo regidos apenas conforme as leis de mercado e constituindo-se, assim, em uma nova arma de política externa - passa a despertar temores nos Estados receptores de seus investimentos - sobretudo os ocidentais desenvolvidos - precisamente a partir da criação de FSI por países de reconhecidas ambições geopolíticas, como China e Rússia (COHEN, 2009). No sentido de justificar a apreensão proveniente da atuação destes atores, o objetivo declarado do Fundo Soberano Brasileiro de "fomentar projetos de

\footnotetext{
${ }_{1}^{1}$ Pode-se considerar o Kuwait Investiment Office como a primeira experiência de um FSI, criado em 1953 a partir da grande acumulação de recursos por este país oriundos da exploração de petróleo (XAVIER JR., 2014).
} 
interesse estratégico do país localizados no exterior" (XAVIER JR., 2014) torna ainda mais evidente a origem de tais preocupações, que refletiriam uma transgressão do supracitado princípio norteador do regime financeiro internacional neoliberal - como já sugerido, uma alocação ótima de capitais cuja origem é a racionalidade de agentes privados, que se pautam na busca por lucro.

Assim, nesse contexto de medo e preocupação acerca da ação dos FSI, um novo desafio coloca-se à governança monetária internacional, na medida em que o objetivo econômico do resguardo do livre fluxo de capitais no sistema financeiro internacional passa a se encontrar ameaçado pela propensão de governos a adotar medidas restritivas, neste âmbito, que visem garantir a segurança de seus países. Em outras palavras, tratar-se-ia de um ambiente propício à adoção de medidas unilaterais de caráter protecionista, visando a restringir a ação desses fundos estatais (COHEN, 2009), o que, como consequência, agiria contra a lógica sustentadora do próprio sistema internacional de finanças.

Nesse contexto, algumas das reações a ações dos FSI, frequentemente vistas como ameaçadoras e geradoras de insegurança, incluem emendas legislativas relacionadas às condições de investimentos financeiros em países como Estados Unidos, Canadá, França, Alemanha e Japão - todos membros do G7 (COHEN, 2009). Não obstante, a percepção geral acerca dos aportes financeiros oriundos dos FSI permanecia associada aos benefícios inerentes a qualquer outra forma de investimento estrangeiro, como o estímulo a atividades econômicas internas ou a criação de empregos. Dessa forma, passa a haver uma coexistência de sentimentos conflitantes acerca da recepção desses investimentos (PARK; ESTRADA 2011).

Diante deste panorama, em prol da manutenção de práticas financeiras saudáveis em um sistema financeiro liberalizado, os países do $\mathrm{G}_{7}$ demandaram ao FMI e à OCDE uma abordagem coletiva que pudesse chegar a um entendimento comum a respeito de uma regulamentação que minimizasse tais conflitos. Para atingir este objetivo, o FMI promoveu a formação do Grupo de Trabalho dos Fundos Soberanos de Investimento, reunindo os maiores FSI do mundo para debater como deveriam ser administrados e estruturados seus investimentos. Em outubro de 2008, uma reunião em Santiago, no Chile, selou um acordo em torno de 24 princípios $^{2}$, que pautariam, a partir de então, as práticas dos FSI: os Princípios de Santiago (COHEN, 2009).

Os Princípios de Santiago fundamentam-se, por conseguinte, no reconhecimento da importância de demonstrar ao mercado financeiro internacional que as decisões de investimento por parte dos FSI estão baseadas em critérios econômicos e financeiros - orientando-se, portanto, conforme lógica do próprio sistema financeiro internacional -, tendo como objetivo abranger um conjunto de princípios e práticas geralmente aceitos quanto à atuação dos mesmos (XAVIER JR., 2014). Nesse sentido, objetivam nortear a ação dos FSI, estabelecendo critérios de ação mais transparentes, que visem garantir um sistema financeiro estável e adequado ao gerenciamento de operações de riscos e investimentos. Despontariam, então, como uma resposta às pressões por medidas protecionistas decorrentes das ações desses fundos

2 O International Forum of Sovereign Wealth Funds (2017) disponibiliza em seu portal na internet a íntegra dos Princípios de Santiago. 
estatais. Um aspecto a se ressaltar, porém, é que esses princípios não proscrevem de forma incondicional os FSI de perseguir objetivos que eventualmente fujam à esfera econômica e financeira, como objetivos sociais ou ambientais - a contrapartida, no entanto, seria a de que fossem claramente explicitados e declarados (PARK; ESTRADA, 2011).

Ponto chave para entender o problema a ser explorado neste artigo é o caráter estritamente voluntário da adesão aos Princípios de Santiago. Este aspecto pode ser em parte explicado pela própria natureza do Grupo de Trabalho dos Fundos Soberanos de Investimento, que também desponta como um corpo voluntário, ad hoc e sem nenhuma autoridade formal acima de si (NORTON, 2010). Tais princípios despontam, assim, apenas como sugestões de boas práticas para o gerenciamento e atuação dos FSI, estando sujeitos, em termos de adesão, à vontade própria de cada Estado (ARIENTI; VIERA, 2013). São aspectos como estes que fizeram com que Cohen (2009) se mostrasse pessimista ao analisá-los quanto a sua eficácia. Além de destacar o ressentimento de alguns governos, que nunca haviam adotado qualquer comportamento suspeito e apresentavam, assim, certa insatisfação com o que consideravam uma intromissão, o próprio autor pondera que, já que ficariam sujeitos à adesão voluntária de cada país, os Princípios de Santiago dificilmente seriam implementados de fato.

Entretanto, as preocupações de Cohen (2009) não se justificaram por muito tempo. Em junho de 2011, o relatório do Fórum Internacional dos Fundos Soberanos de Investimento (FIFSI) - originado a partir do Grupo de Trabalho dos Fundos Soberanos de Investimento - já apontava uma adesão de 95\% das práticas dos FSI aos Princípios de Santiago. Ademais, seguia concluindo que, apesar de a heterogeneidade do grupo não permitir criar expectativas uniformes acerca da implementação dos princípios, estes já constituiriam, de fato, um guia útil aos membros (XAVIER JR., 2014). Isso reflete o fato de que os Princípios de Santiago representam a conformação de um regime para a atuação dos FSI, através do qual os Estados otimizam sua atuação e do qual, portanto, se beneficiam. Ademais, como será argumentado ao longo deste trabalho, o aprofundamento desse regime pode levar à ascensão de uma identidade coletiva entre seus participantes.

\section{SOBRE REGIMES INTERNACIONAIS E IDENTIDADES COLETIVAS}

Esta seção visa a apresentar o arcabouço teórico que fundamenta a hipótese trabalhada neste artigo. Dentro da lógica proposta, tanto a teoria sobre regimes internacionais quanto uma perspectiva construtivista das relações internacionais tornam-se relevantes para uma melhor compreensão em torno do fenômeno representado pelos Princípios de Santiago. Desse modo, em um primeiro momento, discutese as principais ideias apresentadas por Krasner (1982) e por Keohane (1984) acerca de regimes internacionais, ao passo que, na subseção posterior, apresenta-se os principais aspectos do construtivismo positivista de Wendt (1999) que se relacionam como o objetivo deste trabalho. 


\subsection{Os regimes internacionais como ferramenta teórica}

Os regimes internacionais refletem padrões de cooperação e atritos ao longo do tempo (KEOHANE, 1984), de modo que compreender os parâmetros que delimitam e esclarecem o processo de cooperação internacional - que, por sua vez, fundamentam a formação desses regimes - torna-se imprescindível para o desenrolar desta seção. Sobre este tema, Keohane (1984) observa que a crescente interdependência econômica na operação das economias capitalistas modernas cria, com frequência, pontos de tensão entre os Estados. A reação destes, por sua vez, em resposta à demanda interna por proteção de seus interesses, não raramente é a ampliação da atividade estatal, intervindo em setores diversos, visando a solucionar essas tensões. Não obstante, padrões de cooperação podem emergir a partir da existência de interesses complementares, o que afetaria o comportamento dos Estados (KEOHANE, 1984).

A partir das ideias deste mesmo autor, entende-se como cooperação um processo político de coordenação, em cuja origem está um ou mais pontos de conflito, e a partir do qual as políticas de um governo são consideradas por outros como facilitadoras de seus objetivos. Destarte, torna-se relevante estabelecer também a distinção entre cooperação e harmonia, uma vez que esta reflete uma situação em que cooperar é desnecessário, porquanto os comportamentos de atores diversos - que agem conforme seus próprios interesses egoístas - já seriam automaticamente compatíveis com as aspirações uns dos outros. Conflitos e discordâncias, por outro lado, nasceriam de políticas ou ações de terceiros que um governo considera prejudicial à consecução de suas próprias metas. Assim, tendo como objetivo seu próprio auto-interesse, tal governo entraria em um processo de barganha e coordenação com outros, em prol da mitigação destes conflitos. Não obstante, cabe destacar que a cooperação não ocorre apenas em função do auto-interesse, já que a incerteza e as assimetrias no acesso à informação exigem também que se configure instituições cooperativas. Estas, por conseguinte, possuem a importante função de fazer convergir práticas e expectativas de seus membros (KEOHANE, 1984).

Partindo dessa lógica, convém apresentar a definição de Krasner (1982), segundo a qual regimes internacionais constituem-se por princípios, normas, regras e procedimentos de tomada de decisões que promovem a convergência de expectativas em uma determinada área das relações internacionais. Tais elementos, por sua vez, possuem pesos distintos na vigência de um regime, a partir do momento em que princípios e normas são definidores de suas características básicas, enquanto regras e procedimentos podem ser alterados sem interferir na essência do mesmo. Nesse sentido, regimes devem ser entendidos como arranjos com certa permanência ao longo do tempo e capazes de gerar algum sentido de obrigação geral em determinada área. Destarte, alguns teóricos defendem que Estados aderem a determinado regime conscientes da possibilidade de ter que abdicar de interesses de curto prazo, sabendo que outros farão o mesmo em prol do objetivo maior delimitado (KRASNER, 1982).

Para analisar a influência dos regimes sobre comportamentos deles originados e a relação sobre suas variáveis causais básicas, Krasner (1982) apresenta três perspectivas distintas acerca dos mesmos. A primeira delas seria a visão estrutural convencional, que questiona a validade do conceito, considerando- 
o pouco útil, já que tenderia a mascarar as relações de poder nas relações internacionais. Já a corrente estrutural modificada destaca a importância dos regimes em condições específicas, com estes emergindo a partir da coordenação de Estados em áreas particulares de interesse. Por fim, a perspectiva grociana adota uma abordagem mais ampla, considerando como regime qualquer padrão de comportamento humano complexo e recorrente ao longo do tempo. Neste sentido, mesmo o mercado, por exemplo, poderia ser considerado um regime, o que não encontraria respaldo na visão estrutural modificada, que será a levada em consideração nesta análise.

Isso posto, poder-se-ia compreender os princípios como propósitos mais gerais que os países aderentes a um regime têm como objetivo. Normas, ainda que também de caráter genérico, já permitiriam distinguir entre comportamentos legítimos e ilegítimos dentro de uma determinada área. Já as regras seriam mais específicas, indicando com maior precisão os direitos e obrigações dos membros de um determinado regime, enquanto os procedimentos, por sua vez, proporcionam vias de implementação das ações condizentes com os elementos anteriores. Esses diferentes elementos conferem certa complexidade ao conceito de regimes internacionais, a partir do momento em que se interseccionam e, por vezes, se confundem. Desse modo, cada um deles, de diferentes formas e em distintas intensidades, acabam por influenciar o comportamento dos atores nos quais incidem (KEOHANE, 1984).

A partir dessas considerações, três outros aspectos despontam como fundamentais na teoria dos regimes desenvolvida por Keohane (1984). O primeiro deles é que, para esse autor, o estabelecimento de regimes está fortemente associado ao auto-interesse de seus participantes, que percebem nesta cooperação uma via para alcançá-lo ou otimizá-lo - e sem a qual, em contrapartida, dificilmente conseguiriam. O segundo ponto é que o escopo dos regimes internacionais engloba temas diversos que pertencem a um mesmo domínio, fazendo com que os Estados lidem com eles de forma conjunta e até mesmo através de uma mesma burocracia, o que imprime, assim, uma maior coordenação à abordagem de problemas que se tangenciam ou se interseccionam. Por fim, é preciso ter em mente que, nesta teoria, regimes emergem em um mundo de Estados soberanos e em um ambiente de autoajuda, o que confere aos mesmos determinado grau de limitação e fragilidade, já que estarão sempre submetidos à aceitação e dinâmica interna de cada Estado.

Ao discorrer sobre as condições que levam à criação, manutenção e falência de regimes, Krasner (1982) analisa cinco variáveis causais básicas das quais os regimes poderiam ser considerados dependentes, a saber: (1) o auto-interesse egoísta; (2) o poder político; (3) as normas e os princípios; (4) os usos e os costumes; e (5) o conhecimento. Tratam-se de variáveis que podem ou não atuar em conjunto, exercendo maior ou menor peso na eventual formação de um regime. Quanto a este aspecto, por sinal, o autor ressalta que as duas últimas não seriam capazes por si mesmas de impulsionar a criação de um regime, conforme será mais discutido adiante.

A primeira delas, o auto-interesse egoísta, despontaria como a explicação predominante na literatura acerca da formação de regimes e ajuda também a elucidar a observação de Keohane (1984), que destaca, como um dos efeitos de um regime, um maior e melhor acesso a informações por parte de seus 
participantes. Compartilhando da mesma perspectiva, Young (apud KRASNER, 1982) apresenta três caminhos que levariam à formação de regimes. Além da imposição através da força, os outros dois estariam diretamente relacionados à cálculos egoístas: o primeiro, no qual regimes surgiriam a partir de convergência de expectativas individuais e o segundo, que se daria através da negociação de acordos explícitos.

A segunda variável causal seria o poder político e torna-se ilustrativa em teorias como as da estabilidade hegemônica ${ }^{3}$, em que a formação de regimes estaria associada à presença de um poder hegemônico que garantiria, em um primeiro momento, a viabilidade do mesmo. O declínio ou não de um regime como consequência do declínio deste poder dominante, por sua vez, é ponto de divergência entre alguns autores. Stein (apud KRASNER, 1982), por exemplo, sustenta que o declínio hegemônico poderia até mesmo levar a regimes mais fortes, já que os interesses por si só seriam responsáveis por sua manutenção.

Normas e princípios que não estão diretamente associados a determinado regime, mas que o tangenciam ou o influenciam de algum modo também constituiriam uma variável causal. Assim, é possível haver interseções entre regimes ou uma hierarquia entre os mesmos, de modo que um regime pode emergir dentro de uma área das relações internacionais já delimitada por um regime prévio ou mais abrangente. Dessa maneira, ainda que, em um primeiro momento, normas e princípios sejam apresentados como elementos endógenos aos regimes, não se poderia desprezar também a pressão exógena que exercem sobre eles (KRASNER, 1982).

Por fim, os usos e costumes e o conhecimento despontam também como variáveis que, embora incapazes de gerar regimes por si próprias, aparecem como sustentáculos das outras variáveis previamente apresentadas. Dentro dessa lógica, os usos seriam constituídos por padrões regulares de comportamento baseados na prática efetiva, ao passo que costumes são categorizados como práticas recorrentes de longo prazo. Como consequência, as expectativas compartilhadas a partir de tais fatores possuiriam caráter normativo relacionado a determinado regime. Já o elemento do conhecimento, via de regra, é tratado como variável interveniente e é apresentado como um conjunto de informações técnicas e das teorias associadas às mesmas que gera consenso em torno de alguma meta, norteando, assim, objetivos a serem alcançados (KRASNER, 1982).

As teorias sobre regimes internacionais, contudo, não passam incólumes a críticas de outros teóricos. Nesse sentido, tendo em mente a finalidade deste trabalho, convém destacar a que faz Strange (1982), para quem a noção de regimes promove uma série de distorções da realidade. Algumas delas, por exemplo, se assentariam na imprecisão do termo - ainda que a própria autora reconheça o esforço de Krasner (1982) para saná-la, ao qual se somaria a análise de Keohane (1984) - e no fato deste conferir um aspecto estático à realidade, o que não encontraria correspondência no mundo real. Ademais, os regimes internacionais partiriam de uma visão estadocêntrica das relações internacionais - como se apenas dos Estados dependessem os parâmetros de organização da realidade -, estando também repleta de vieses

3 Para mais informações, ver Kindleberger (1973), "The World in Depression". 
que visariam a atender os interesses dos Estados Unidos - de onde se originam a maior parte dos estudos sobre regimes internacionais. Entretanto, como se verá na próxima seção, estas críticas não apenas não invalidam a análise que se propõe, mas a fortalecem. Antes que se proceda a ela, contudo, torna-se relevante apresentar a outra perspectiva teórica com a qual este trabalho dialoga - o construtivismo positivista.

\subsection{A identidade coletiva a partir do construtivismo positivista}

A reflexão que se pretende estabelecer acerca da conformação de uma identidade coletiva proveniente dos Princípios de Santiago possuirá como marco teórico o construtivismo positivista de Alexander Wendt (1999). Na origem desta teoria, há a ideia de que a construção social do mundo em que vivemos ocorre mediante o processo de socialização, que promove a formação de identidades e interesses dos agentes que o compõem. Tais identidades são aprendidas e reforçadas através de um processo de espelhamento, no qual um ator reflete, a partir da interação social, a avaliação supostamente feita pelo outro, originando um encadeamento de interações desta mesma natureza ${ }^{4}$. Desse modo, pode-se dizer que a prática da socialização e as identidades e interesses dos agentes se constituem mutuamente, promovendo a formação de uma estrutura intersubjetiva de conhecimento, que, por sua vez, molda o mundo socialmente construído do qual fazemos parte. Dentro dessa lógica, se, em uma primeira interação social, um agente trata o outro como inimigo, este provavelmente internalizará tal papel identitário nesta socialização - ao mesmo tempo em que poderia assumir identidades distintas em outras interações (WENDT, 1999).

O que Wendt (1999) entende como processo - como agentes estatais e culturas sistêmicas são sustentados por práticas de política externa e, eventualmente, transformados - é, não obstante, a chave para se compreender a análise que se propõe nesta seção. A partir da socialização entre Estados, culturas sistêmicas ${ }^{5}$ emergem e, apesar de suas propriedades homeostáticas, podem ser total ou parcialmente transformadas ao longo do tempo. Desse modo, a mudança de uma cultura hobbesiana para uma cultura lockeana, assim como uma eventual transformação desta para uma cultura kantiana, seriam exemplos ilustrativos de como os Estados, periodicamente, podem fazer algo novo da anarquia na qual vivem. A maneira como tais mudanças ocorrem, no entanto, podem ser explicadas por meio de duas abordagens distintas e não mutuamente excludentes: o racionalismo e o construtivismo (WENDT, 1999).

A diferença fundamental entre tais perspectivas consiste na ideia de que, na visão racionalista, os agentes são exógenos ao processo, enquanto uma perspectiva construtivista os trataria como endógenos. Isso significa que, em termos racionalistas, as identidades e os interesses de um agente não estariam

\footnotetext{
4 Tratam-se, respectivamente, dos conceitos de "mirroring" e "reflected appraisals" trabalhados por esse autor em Social theory of international politics (1999).

$5 \mathrm{Na}$ mesma obra supracitada, Wendt identifica, na política internacional, três estruturas ou culturas sistêmicas para demonstrar o aspecto socialmente construído da anarquia. Em um primeiro momento, uma cultura hobbesiana encontraria mais condições de emergir a partir dos primeiros processos de socialização. A cultura lockeana, por sua vez, diminuiria o aspecto conflitivo daquela, enquanto, por fim, o vislumbre de uma cultura baseada nas ideias de Kant dá prosseguimento às reflexões do autor.
} 
continuamente em processo e nem seriam sustentados pela própria interação social. Seriam, assim, préconcebidos e imunes à influência de determinada socialização. A abordagem construtivista, por sua vez, entende que esta interação sustenta a concepção que tais agentes possuem de si próprios e dos outros, atuando diretamente sobre suas identidades e seus interesses. Desse modo, tal processo pode imprimir mudanças nessas identidades, o que, nesse sentido, é o que permite compreender os agentes de maneira endógena. Não obstante, como os efeitos do processo podem ou não afetar a identidade dos agentes, a perspectiva construtivista não exclui a visão racionalista. Esta seria apenas um caso especial de socialização em que tal mudança não ocorre, consistindo, assim, em uma escolha metodológica na qual identidades e interesses são previamente dados. Em outras palavras, o processo de cooperação entre Estados, por uma abordagem racionalista, teria apenas efeitos comportamentais e não em suas identidades e interesses prévios, ao passo que, para a construtivista, estes seriam mutuamente constitutivos ao processo (WENDT, 1999).

À luz dessas distintas abordagens, os meios através dos quais mudanças nas estruturas intersubjetivas de conhecimento podem ocorrer se tornam mais compreensíveis. Tratam-se de modelos evolucionários que permitem entender a transmissão de variações de identidade gerados em um nível unitário para níveis macro ou populacionais. Uma dessas formas, a seleção natural, promoveria o aspecto da autoajuda como essencial para a sobrevivência dos agentes, ao passo que a seleção cultural, que engloba processos de imitação e de aprendizagem social, abriria espaço para cooperação entre os mesmos (WENDT, 1999). Para os propósitos deste artigo, as reflexões do teórico acerca da aprendizagem social despontam como fundamentais.

Assim, sob uma perspectiva racionalista, a aprendizagem social, com efeitos comportamentais em termos de cooperação, promoveria aos agentes o acesso a novas informações, de modo que poderiam atingir mais efetivamente seus objetivos. Trata-se, por assim dizer, de um processo de aprendizagem simples. Quando esta cooperação, no entanto, muda suas identidades e seus interesses, estamos diante de uma aprendizagem complexa, que promove a internalização de uma nova cultura. Esta, por sua vez, se reproduzirá automaticamente por meio dos processos de espelhamento e avaliações refletidas. Desse modo, quando tal cultura cooperativa é desafiada, os agentes reagem de modo a defendê-la. Ter-se-ia formada, por conseguinte, uma identidade coletiva, que, com implicações comportamentais, dispõe de escopo limitado à área ou ao domínio temático em torno do qual emergiu. Ressalta-se, por fim, que esta identidade coletiva estaria sempre em conflito com o caráter individualista das identidades que contempla, o que poderia tornar problemático o sacrifício de necessidades individuais em nome das coletivas (WENDT, 1999).

\section{UMA PROPOSTA PARA A COMPREENSÃO DOS PRINCÍPIOS DE SANTIAGO}

Tendo em mente as perspectivas teóricas apresentadas, esta seção visa a dar prosseguimento à verificação da hipótese proposta por este artigo a partir da compreensão dos Princípios de Santiago nos termos de um regime internacional em formação, que pode ser o fundamento de uma nova identidade 
coletiva. Isto posto, deve-se ressaltar que não é um objetivo deste artigo restringir tais opções teóricas como as únicas válidas para compreendê-los - devendo-se este exercício, pelo contrário, estimular outras aplicações teóricas que também sirvam ao propósito de melhor elucidar a realidade em que vivemos. Não obstante, como se demonstrará na discussão a seguir, tais teorias despontam como valiosas ferramentas para as finalidades desta pesquisa.

\subsection{O regime internacional dos Princípios de Santiago}

O processo de cooperação que trouxe como proposta os Princípios de Santiago pode, por conseguinte, ser melhor compreendido à luz do panorama teórico apresentado acerca de regimes internacionais. Conforme ressaltado por Keohane (1984), o conflito é elemento inerente a qualquer impulso inicial para a cooperação. Nesse sentido, a ameaça e sinalização de protecionismo financeiro por países que desconfiavam de motivações políticas e estratégicas por detrás das ações de FSI (COHEN, 2009) constitui-se como o conflito propulsor do processo de cooperação que deu origem ao estabelecimento do que pode ser entendido como um regime internacional. As ideias de Krasner (1982) e Keohane (1984) também são consonantes com o caráter de previsibilidade refletido nesses princípios, que visam a promover maior transparência acerca das práticas dos FSI, assim como das expectativas geradas por sua atuação (PARK; ESTRADA, 2011).

A partir desses esclarecimentos, a estrutura dos Princípios de Santiago como um regime internacional pode se tornar mais clara, uma vez que é compatível com a definição apresentada por Krasner (1982). Partindo de princípios mais gerais concernentes à liberalização do sistema financeiro internacional - cuja manutenção, ao final das contas, foi o que motivou sua criação -, chega-se a normas que, conforme estabelecido por Keohane (1984), já permitem distinguir comportamentos legítimos dos que seriam, em tal regime, ilegítimos. Desse modo, qualquer ação de investimento por parte dos FSI que não obedeça a critérios econômicos e financeiros, pautados assim por uma lógica de riscos e lucro, poderia ser considerada ilegítima - salvo as exceções apresentadas na seção precedente, como as que incluiriam metas ambientais ou sociais, mas que devem obedecer a uma série de contrapartidas. No mesmo sentido, as normas e procedimentos que constituem este regime encontram-se distribuídos entre os 24 princípios, que, divididos em 3 partes, podem ser sumarizados da seguinte maneira: a primeira seção contempla a estrutura legal e os objetivos e coordenação dos FSI com políticas macroeconômicas; a seção subsequente abrange regras relacionadas à estrutura institucional e de governança; já a terceira parte apresenta considerações acerca do gerenciamento de riscos e investimentos (NORTON, 2010). Identificados, assim, este conjunto de princípios, normas, regras e procedimentos, pode-se seguir explorando as ideias de Krasner (1982), agora sobre os mecanismos causais que geraram a ascensão deste regime.

Acerca deste tema, dentre as cinco variáveis causais básicas apresentadas por este autor, o autointeresse egoísta pode ser considerado como o grande catalisador da formação do regime em questão, o que se coaduna também com a teoria de Keohane (1984). Isso porque, ao se considerar as polêmicas advindas da ação dos FSI, esquece-se frequentemente de que, ao final e ao cabo, se está tratando de 
fundos de investimentos. Conforme discutido na primeira seção deste artigo, na origem destes fundos está o objetivo de um melhor gerenciamento das grandes reservas internacionais acumuladas por determinados países, que deveriam ser otimizadas em termos de lucro. Nesse sentido, a meta principal dos FSI seria maximizar os retornos oriundos de seus investimentos, o que é plenamente consistente com o comprometimento com as orientações propostas pelos Princípios de Santiago, já que estes oferecem a tranquilidade e as garantias demandadas pelos países receptores dos mesmos. Em outras palavras, a adesão a esse regime confirma e reforça o fato de que os FSI são entidades essencialmente comerciais com o objetivo de gerar lucro para seus governos, funcionando, assim, como um mecanismo de otimização e consecução de seus auto-interesses egoístas (PARK; ESTRADA, 2011).

Não obstante, não se pode desprezar o papel exercido pelas outras variáveis causais apresentadas por Krasner (1982) na conformação deste regime. No caso do poder político, conforme apontado na seção anterior deste trabalho, o impulso inicial que coloca a formação de um Grupo de Trabalho dos Fundos Soberanos de Investimento em pauta no FMI e na OCDE provém precisamente do G-7. Ademais, normas e princípios exógenos a este regime também atuaram como propulsores para a sua formação, uma vez que os Princípios de Santiago visam a garantir a manutenção de um dos pilares dos regimes monetário e financeiro internacionais, que é a não intervenção estatal nos mesmos (ARIENTI; VIERA, 2013). Usos e costumes associados a estes regimes citados, que se vêm consolidando desde a década de 1980, assim como o arcabouço teórico de doutrinas econômicas ortodoxas - que, sustentadoras da lógica neoliberal, fundamentam a ideia de um sistema financeiro liberalizado (GILPIN, 2001) -, despontariam, do mesmo modo, como variáveis associadas à ascensão do regime internacional analisado. Torna-se claro, portanto, que, embora o auto-interesse egoísta possa ser considerado como a variável causal determinante para a conformação dos Princípios de Santiago como um regime, outros fatores também reforçaram esta tendência.

Diante da lógica apresentada, pode-se também esclarecer que as críticas de Strange (1982) não se sustentam a partir da análise deste regime em especial. Isso porque, em primeiro lugar, a concepção estadocêntrica denunciada pela autora faz, nesse caso, perfeito sentido, uma fez que os FSI são efetivamente geridos por Estados, o que faz com que tal regime dependa majoritariamente da ação e da vontade destes - diferentemente de outras áreas justamente destacadas pela autora, como o comércio ou o sistema financeiro em suas diversas vertentes. Em segundo lugar, a suposta imprecisão do termo se esvai diante da observação de cada um dos Princípios de Santiago, que visam a detalhar de forma clara os moldes para a ação dos FSI, agindo, por conseguinte, em direção contrária à ponderação da autora. Finalmente, a ideia de que tal regime é enviesada e atende aos interesses imperiais dos Estados Unidos que é respaldada por análises mais recentes na Economia Política Internacional ${ }^{6}$ - é verossímil, mas não invalida ou desconstrói a existência do regime - pelo contrário, ajudaria a melhor compreendê-lo.

Logicamente, a eficácia de tais princípios como um regime depende, ainda, diretamente da qualidade dos procedimentos e processos inerentes a seu funcionamento. Nesse sentido, a criação de um

\footnotetext{
${ }^{6}$ Sobre a referida perspectiva, ver, por exemplo, Konings (2011), para quem a globalização financeira é uma expansão do modelo de organização financeira dos Estados Unidos, atendendo, assim, aos interesses imperiais deste país.
} 
Fórum Secretariado voluntário e permanente - o já mencionado FIFSI -, que passou a gerar um procedimento contínuo de avaliação e adequação de práticas dos FSI aos Princípios de Santiago, busca aprofundar e internalizar de forma mais efetiva seus princípios e práticas (NORTON, 2010). Tal situação proporcionaria a identificação dos aderentes a este regime nos termos da existência de um clube, com suas regras e benefícios intrínsecos (Ibidem), o que, permite, a partir disso, vislumbrá-lo nos moldes de uma identidade coletiva em construção.

\subsection{A caminho de uma identidade coletiva?}

Tendo-se compreendido os Princípios de Santiago como um regime internacional, a análise que agora se propõe pauta-se em entendê-lo como catalisador de uma identidade coletiva que contemplaria a atuação dos FSI. Em conformidade com a teoria de Wendt (1999), o que os Princípios de Santiago propõem é uma nova forma de socialização entre os Estados, na figura de seus fundos soberanos. Por exemplo, conforme já apresentado nas seções precedentes, esta socialização incluiria uma maior transparência em relação à atuação desses fundos, que devem agir de acordo com critérios econômicos e financeiros. Assim, dentro da lógica estabelecida pelo autor, os atos cooperativos destes agentes gerariam, por meio dos mecanismos de espelhamento e de avaliações refletidas, uma nova estrutura intersubjetiva de conhecimento que mitigaria as percepções negativas advindas dos temores que Estados receptores dos investimentos desses fundos apresentam. O aspecto mutuamente constitutivo dessas práticas sociais e da estrutura intersubjetiva de conhecimento, por sua vez, teria desdobramentos no sentido de reproduzir e reforçar os atos em conformidade com os Princípios de Santiago - já que tais culturas possuem, por si próprias, propriedades homeostáticas que promovem sua autopreservação (WENDT, 1999).

A conformação de uma identidade coletiva, não obstante, estaria sujeita aos impactos da forma de socialização proposta pelo regime nas identidades e interesses dos Estados aderentes a ele. A partir daí, conforme Wendt (1999), as duas abordagens apresentadas proporcionarão visões distintas acerca deste processo. Segundo uma perspectiva racionalista, as identidades e os auto-interesses dos Estados que aderem aos Princípios de Santiago seriam exógenos ao processo de socialização a que estes dariam origem. Nesse sentido, por meio do que Wendt (1999) apresenta como uma aprendizagem simples, tal regime impactaria tão somente no comportamento dos Estados uns com os outros, que estariam agindo em prol de seus já comentados objetivos de obter a maior margem de lucro possível a partir de seus investimentos. Esta abordagem, por conseguinte, não vislumbra a ascensão de uma identidade coletiva em torno dos Princípios de Santiago, o que, na prática, significa que um eventual fim deste regime conduziria os Estados a retomarem seus comportamentos prévios ao mesmo. Em outras palavras, permaneceria o risco de, no futuro, ameaças de protecionismo financeiro frente às ações de FSI retornarem à pauta.

Não obstante, à luz de uma perspectiva construtivista, pode-se especular acerca do surgimento de uma identidade coletiva a partir deste regime. Este fenômeno estaria associado à aprendizagem complexa da socialização proposta pelos Princípios de Santiago, que modificariam e constituiriam as identidades e 
os interesses dos Estados que a ele aderem. Em outras palavras, tais princípios seriam incorporados pela identidade desses Estados, que veriam a adoção e propagação dos mesmos como sendo seus próprios interesses. A socialização decorrente desse processo, por sua vez, permite o vislumbre de um contexto em que, na ausência da existência desses princípios de maneira formal, os Estados continuarão a implementálos, uma vez que os terão como parte de suas identidades. Tal seria a situação em que uma identidade coletiva estaria formada, fazendo com que os Estados, em conformidade com a teoria de Wendt (1999), teriam internalizado esta cultura, passando a defendê-la em nome de seus próprios interesses. Evidentemente, ainda em consonância com as ideias deste teórico, tal processo demandaria tempo para se concretizar, o que, dado o espaço de tempo existente entre o lançamento desses princípios e a elaboração deste artigo, poderia tornar uma perspectiva racionalista, a priori, mais adequada. O que se pode inferir a partir dos fatos apresentados neste trabalho ao confrontá-los com tal teoria, não obstante, é que os Princípios de Santiago abrem o caminho para que esta identidade coletiva se construa e gere os benefícios dela proveniente.

\section{DESDOBRAMENTOS EMPÍRICOS}

Conquanto o período de tempo, conforme sinalizado, seja curto para se estabelecer considerações acerca da conformação de uma identidade coletiva, o FIFSI vem disponibilizando um acompanhamento periódico da aplicação dos Princípios de Santiago, que pode ser esclarecedor para o argumento aqui desenvolvido. Contando com mais de $30 \mathrm{FSI}$ como membros, o fórum tem como uma de suas propostas a promoção de um auto-monitoramento voluntário que demonstra o comprometimento dos principais fundos soberanos do mundo com esses princípios. Em outras palavras, trata-se de um esforço conjunto para conferir maior transparência e medir a adesão ao regime estabelecido, o que, consequentemente, contribui com o desenvolvimento de uma identidade coletiva nele fundamentada.

Como mencionado na segunda seção deste artigo, já em 2011 o FIFSI apontava que 95\% das práticas dos principais FSI se mostravam em conformidade com os Princípios de Santiago. Entretanto, Truman (2013) observou que, embora tivesse havido progressos no sentido de alinhamento aos princípios por parte dos fundos soberanos, os dados apresentados pelo FIFSI eram exagerados e sua metodologia demandava uma maior consistência. De fato, sua crítica ressaltava a necessidade de se proceder a estudos de caso que efetivamente comprovassem um comprometimento, que ainda não estava claro, com o regime que se buscava solidificar.

Sanando esses questionamentos, o FIFSI apresentou, em 2014 e 2016, relatórios que avaliaram como os FSI vinham implementando os Princípios de Santiago a partir da análise de 20 estudos de casos $^{7}$ de seus membros. Conforme destacado pelos documentos, a análise do progresso em termos de adequação ao regime pelos fundos levou em consideração as distintas trajetórias históricas e estruturas

\footnotetext{
7 Conforme os dois documentos, os casos estudados contemplam os FSI de: Austrália, Azerbaijão, Botsuana, Canadá, Chile, Iran, Coreia do Sul, Kuwait, Nova Zelândia, Noruega, Qatar, Cingapura, Timor-Leste, Trinidad e Tobago, Estados Unidos, China, Irlanda, Cazaquistão, Marrocos e Palestina.
} 
legais de seus respectivos países. Nesse sentido, a proposta de auto-monitoramento do fórum vai além de critérios quantitativos, levando-se em conta tal processo de maneira contextualizada para cada país. Isso posto, o que se pode observar a partir dos casos estudados é que os FSI vêm atuando em conformidade com o regime dos Princípios de Santiago, o que pode ser percebido a partir de critérios legais, institucionais e/ou de gerenciamento de risco e de investimentos (FIFSI, 2014; 2016).

Com efeito, os documentos transparecem que a gestão desses fundos, a despeito de sua natureza estatal, ocorre, via de regra, em consonância com o modus operandi prevalecente no sistema financeiro internacional, deixando clara suas atuações como fundos de investimentos - o que, ao final e ao cabo, atende ao propósito original dos princípios como regime e da identidade que se busca construir. Tal é o aspecto ressaltado, por exemplo, pelo FSI da China, o China Investment Corporation, para quem os Princípios de Santiago são de grande valor nesse sentido (FIFSI, 2016, p. 23): "[...] temos construído uma imagem favorável como investidor institucional comercial e responsável, o que se torna uma via de atração de parceiros que compartilham dessa perspectiva e facilita nossos investimentos pelo mundo."

O que se pode perceber, portanto, diante desse panorama, é que a consolidação do regime analisado neste artigo vem evoluindo e começa, ao longo da primeira década de sua existência, a ser respaldada pela realidade. Ainda que, conforme destacado por Strange (1982), a observação de um regime transmita a ideia da existência de uma estrutura estática, a própria proposta de auto-monitoramento demonstra o caráter evolucionário e fluido de adesão ao mesmo. Com efeito, por ser uma iniciativa voluntária que parte dos próprios FSI, torna-se clara a existência dessa percepção e preocupação por parte dos participantes e construtores desse regime, o que torna ainda mais provável sua incorporação às respectivas identidades de seus participantes.

\section{CONCLUSÃO}

As teorias de relações internacionais têm especial relevância para uma melhor compreensão de fenômenos novos, em que há poucos precedentes históricos que possam guiar nossos pensamentos (MEARSHEIMER; WALT, 2013). Nesse sentido, a formulação dos Princípios de Santiago, diante de todas as condições que a envolveram, constituiu-se em uma experiência inteiramente nova para todas as partes envolvidas (NORTON, 2010). Assim, para compreender esse fenômeno, este artigo analisou os Princípios de Santiago à luz das teorias de Krasner (1982) e Keohane (1984), confirmando a hipótese de que tais princípios representam um primeiro passo no estabelecimento de um regime internacional. Esta ação, conforme discutido, parte da necessidade de se manter o sistema financeiro internacional aberto ao livre fluxo de capitais, proporcionando um mecanismo de adequar as práticas de investimento dos FSI a este objetivo (ARIENTI, VIERA, 2013), o que vem sendo respaldado pelos dados apresentados pelo FIFSI em seus relatórios até 2016 .

Desse modo, o medo e a desconfiança em torno da ação desses atores se soluciona - sanando as dúvidas de Cohen (2009) - com a adesão voluntária a um regime que traz benefícios a todos os 
participantes. Por fim, este artigo conclui também que este regime internacional pode, ademais, promover, no longo prazo, a formação de uma identidade coletiva. Isso porque a nova forma de socialização por ele propagada pode, em conformidade com a teoria de Wendt (1999), impactar de forma mais profunda nos Estados a ele aderentes. Tal situação conferiria aos Princípios de Santiago uma sobrevivência prolongada, uma vez que passariam a constituir a identidade e os interesses dos Estados que o adotam. Resta saber, assim, analisando os desdobramentos deste regime, em que medida isso se tornará realidade.

* Artigo recebido em $27 \mathrm{fev} 2018$, aprovado em 24 abr 2018.

\section{REFERÊNCIAS}

ARIENTI, Patrícia F. F.; VIERA, Luan. A economia política dos Fundos de Riqueza Soberana. Contexto Internacional, v. 35, n. 1, Rio de Janeiro, Jan./Junho 2013.

CARVALHO, Fernando C. de. Mudanças no papel e nas estratégias do FMI e perspectivas para países emergentes. In: FERRARI FILHO, Fernando; DE PAULA, Luiz F. (orgs.). Globalização financeira: ensaios de macroeconomia aberta. Editora Vozes, 2004.

COHEN, Benjamin J. Sovereign wealth funds and national security: the Great Tradeoff. International Affairs, 85:4, 2009, pp: 713-731.

FUNDS, International Forum of Sovereign Wealth. Santiago Principles. Disponivel em: $<$ http://www.ifswf.org/santiago-principles-landing/santiago-principles> Acessado em 14 de janeiro de 2018.

.15 case studies. 2014. Disponível em:

<http://www.ifswf.org/sites/default/files/SantiagoP15CaseStudies1_o.pdf> Acessado em 19 de abril de 2018.

. Implementing the Santiago Principles. 2016. Disponível em:

<http://www.ifswf.org/sites/default/files/IFSWF_CaseStudies_Nov2016_o.pdf> Acessado em 20 de abril de 2018.

GILPIN, Robert. Global political economy: understanding the international economic order. Princeton University Press, 2001. 
KEOHANE, Robert O. After Hegemony: cooperation and discord in the world political economy. Princeton: Princeton University Press, 2005.

KONINGS, Martijn. The development of American finance. Cambridge: Cambridge University Press, 2011.

KRASNER, Stephen G. Structural Causes and Regime Consequences: Regimes as Intervening Variables. International Organization, v. 36, n. 2, International Regimes, Spring 1982, pp: 185-205.

MEARSHEIMER, John J; WALT, Stephen M. Leaving Theory Behind: Why Hypothesis Testing Has Become Bad for IR. European Journal of International Relations, v. 19, n. 3, 2013, pp: 427-457.

NORTON, Joseph F. The Santiago Principles for Sovereign Wealth Funds: A case study for internacional financial standart-setting processes. Journal of International Economic Law, v. 13, n. 3, 2010.

PARK, Donghyun; ESTRADA, Gemma E. Developing Asia's Sovereign Wealth Funds: The Santiago Principles and the case for self-regulation. Asian Journal of International Law, v. 1, n. 2, junho de 2011, pp: 383-402.

STRANGE, Susan. Cave! Hic Dragones: A Critique of Regime Analysis. International Organization, v. 36, n. 2,1982 .

TRUMAN, Edwin M. Implementation of the Santiago Principles for Sovereign Wealth Funds. Peterson Institut for International Economics, 2013. Disponível em:

$<$ https://piie.com/sites/default/files/publications/pb/pb13-31.pdf> Acessado em 19 de abril de 2018.

WENDT, Alexander. Social Theory of International Politics. Cambridge: Cambridge University Press, 1999.

XAVIER JR., Ely C. Fundos Soberanos de Investimento e imunidade de jurisdição. Revista Direito GV, v. 10, n. 1, SãoPaulo, Jan./Junho 2014. 